\title{
Molecular Conformation of Crystalline and Amorphous Chloramphenicol
}

\author{
Emilio Meaurio, Eva Sanchez-Rexach, Jone Muñoz, Jose-Ramon Sarasua \\ Department of Mining-Metallurgy Engineering and Materials Science, POLYMAT \\ School of Engineering, University of the Basque Country (UPV/EHU) \\ Alameda Urquijo s/n, Bilbao, Spain \\ emiliano.meaurio@ehu.eus; evagloria.sanchez@ehu.eus; jone.munoz@ehu.eus; jr.sarasua@ehu.eus
}

\begin{abstract}
This paper investigates the conformational behavior of chloramphenicol (CHL) both in the condensed phases and in vaccum using FTIR spectroscopy and ab initio QM methods. Existing literature reports two possible conformations in the crystalline phase, reported both in 1979 by Chatterjee et al. (J. Cryst. Mol. Struct., 1979, 9:295-304) and by Acharya et al. (Acta Cryst., 1979, B35:13601363). The analysis of the infrared spectrum of crystalline CHL supports the conformation proposed by Chatterjee, characterised by an intramolecular $\mathrm{O}-\mathrm{H} \cdots \mathrm{O}$ hydrogen bond in which the primary hydroxyl group acts as hydrogen bond donor, and is not compatible with the geometry reported by Acharya. The conformational behavior of CHL in the liquid phase has been analyzed using the Onsager selfconsistent reaction field (SCRF) model. The release from the intermolecular interactions occurring in the crystalline phase results in the reversal of the intramolecular $\mathrm{O}-\mathrm{H} \cdots \mathrm{O}$ hydrogen bond in $\mathrm{CHL}$ so that the secondary hydroxyl group acts as hydrogen bond donor. In addition, the dichloroacetamide group folds back further over the phenyl ring to form an intramolecular $\mathrm{C}-\mathrm{Cl} \cdots \pi$ halogen bond.
\end{abstract}

Keywords: Chloramphenicol (CHL), Conformation, Interactions, Molecular Modeling.

\section{Introduction}

Chloramphenicol (CHL) is a broad-spectrum antibiotic, currently included in List of Essential Medicines (EML) published by the World Health Organization (WHO) [1]. Originally isolated from Streptomyces venezuelae in 1947 [2, 3], its structure (shown in Fig. 1) was soon elucidated and became the first antibiotic to be synthesized by chemical means [2, 3]. CHL acts essentially as a bacteriostatic agent, inhibiting bacterial synthesis by binding to the 50S subunit of $70 \mathrm{~S}$ ribosomes [2]. The bacterial activity of CHL has been suggested to depend on the conformation of the propanediol moiety $[2,3]$.

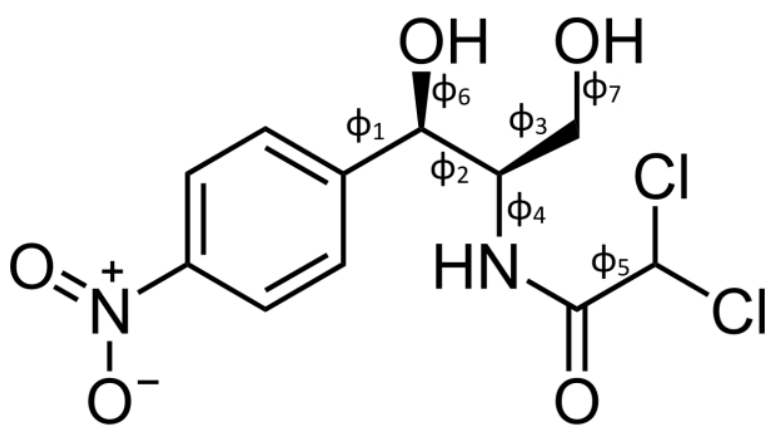

Fig. 1: Chemical structure of CHL, showing the seven rotatable dihedrals considered in this work.

The conformational analysis of CHL should be of high interest to broad synthetic/medicinal chemists and chemical biologists who aim for design and development of new antibiotics [4, 5]. However, since the conformational behavior of pure CHL was investigated several decades ago using only experimental techniques and quite outdated computational 
methods $[6,7,8,9,10,11,12]$, currently there is no consensus on the actual conformation of free CHL molecules in solution [2]. Jardetzky [9] concluded by means of NMR spectroscopy the presence of a unique intramolecularly hydrogen bonded CHL conformer in solvents of different polarity ranging from acetone to water. However, using NMR spectroscopy and molecular modeling calculations Bustard [10] and Höltje [11] concluded the existence of a second conformer devoid of intramolecular hydrogen bonding. Hahn claimed a definitive study in view of these contradictory reports [2]. The lack of consensus also extends to the solid phase: Chatterjee [7] proposed an intramolecularly hydrogen bonded conformer in which the primary hydroxyl group acts as hydrogen bond donor, but Acharya [8] reported the secondary hydroxyl as the actual hydrogen bond donor. None of these crystalline structures has been discarded, and both are considered in the current literature [2].

This paper revisits the conformational behavior of CHL in the crystalline phase and in the free molecules in solution, solving the contradictory results found in the literature and stablishing the correct conformational features of CHL. FTIR spectroscopy is used to discriminate between the two crystallines structures currently accepted $[7,8]$. The conformational behavior of free CHL molecules in solution is analyzed using the Onsager self-consistent reaction field (SCRF) model.

\section{Experimental Section \\ 2.1. Starting Materials}

Chloramphenicol (purity $\geq 98 \%$ ) and acetonitrile were supplied by Aldrich Chemical Corp. (Spain) and were used as received.

\subsection{Fourier Transform Infrared Spectroscopy (FTIR)}

FTIR spectra were recorded on a Nicolet AVATAR 370 FTIR spectrophotometer with a resolution of $2 \mathrm{~cm}^{-1}$, averaged over 64 scans in the $4000-450 \mathrm{~cm}^{-1}$ range. Pure CHL FTIR samples were prepared by grinding CHL with KBr and pressing. The absorbance of the samples was within the range where the Lambert-Beer law is obeyed. A controlled high temperature transmission cell mounted in the spectrometer was used to melt CHL and to subsequently obtain the spectra of the supercooled samples. Spectra in solution was recorded from $1 \mathrm{wt} \%$ CHL solutions in acetonitrile using a variable path length cell equipped with IR grade Silicon windows ( $2 \mathrm{~mm}$ thick). Second derivative spectra were smoothed using the NorrisWilliams Gap Derivatives.

\subsection{Quantum Chemistry Methods.}

$A b$ initio calculations were performed using the Firefly QC package [13]. Geometry optimizations were carried out using the hybrid DFT method B3LYP-D3/DZP, consisting on the B3LYP functional extended with the D3 version of Grimme's dispersion correction. The DZP basis function is based on the DZ basis function of Dunning [14] plus one set of polarization functions with the exponents recommended by Dunning for correlated calculations: $\mathrm{H}(\mathrm{p})$ 0.935; $\mathrm{C}$ (d) 0.550 ; $\mathrm{N}$ (d) 0.817 ; $\mathrm{O}$ (d) 1.185; $\mathrm{Cl}$ (d) 0.600. Vibrational mode analyses have been carried out at the B3LYP-D3/def2-TZVP(-f) (-f means without f polarization functions) [15].

\section{Results and Discussion.}

\subsection{FTIR Analysis of Crystalline CHL.}

The analysis of the crystal structure of CHL was first attempted by Dunitz [6], but the atomic coordinates were actually reported a few years later by Chatterjee [7] and Acharya [8]. CHL crystallizes in the orthorhombic space group C222 ${ }_{1}$, with $\mathrm{a}=17.495 \AA, \mathrm{b}=7.321 \AA, \mathrm{c}=22.130 \AA$, and $\mathrm{Z}=8$ [7], adopting a conformation in which the dichloroacetamide moiety is folded back over the phenyl ring. Following the usual practice, both authors [7, 8] determined the location of the heavy atoms by means of the X-Ray diffraction data, but the location of the Hydrogen atoms was guessed from the molecular structure. However, since the location of the hydroxyl hydrogens is particularly difficult to assess, they proposed different orientations for the $\mathrm{OH}$ groups, resulting in two different conformers with different association patterns in the crystalline structure (Fig. 2). Both conformers present an intramolecular $\mathrm{O}-\mathrm{H} \cdots \mathrm{O}-\mathrm{H}$ hydrogen bond, but in the conformer proposed by Chatterjee the primary hydroxyl acts as donor (Fig. 2a) [7] while in the conformer proposed by Acharya the donor is the secondary hydroxyl (Fig. 2b). Regarding the intermolecular association in the crystalline structure, both models present an intermolecular $-\mathrm{N}$ $\mathrm{H} \cdots \mathrm{O}-\mathrm{H}$ hydrogen bond (to primary $\mathrm{OH}$, Fig. $6 \mathrm{a}$ and $6 \mathrm{~b}$ ) $[7,8]$. However, the model of Chatterjee presents an intermolecular 
$-\mathrm{O}-\mathrm{H} \cdots \mathrm{O}=\mathrm{C}$ hydrogen bond in which the secondary $\mathrm{OH}$ acts as donor (Fig.6a) [7] while the model of Acharya presents an intermolecular $-\mathrm{O}-\mathrm{H} \cdots \mathrm{Cl}$ hydrogen bond in which the primary $\mathrm{OH}$ acts as donor (Fig. 6b) [8]. Both structures have received similar attention in the literature, and none has been discarded yet $[16,17]$.
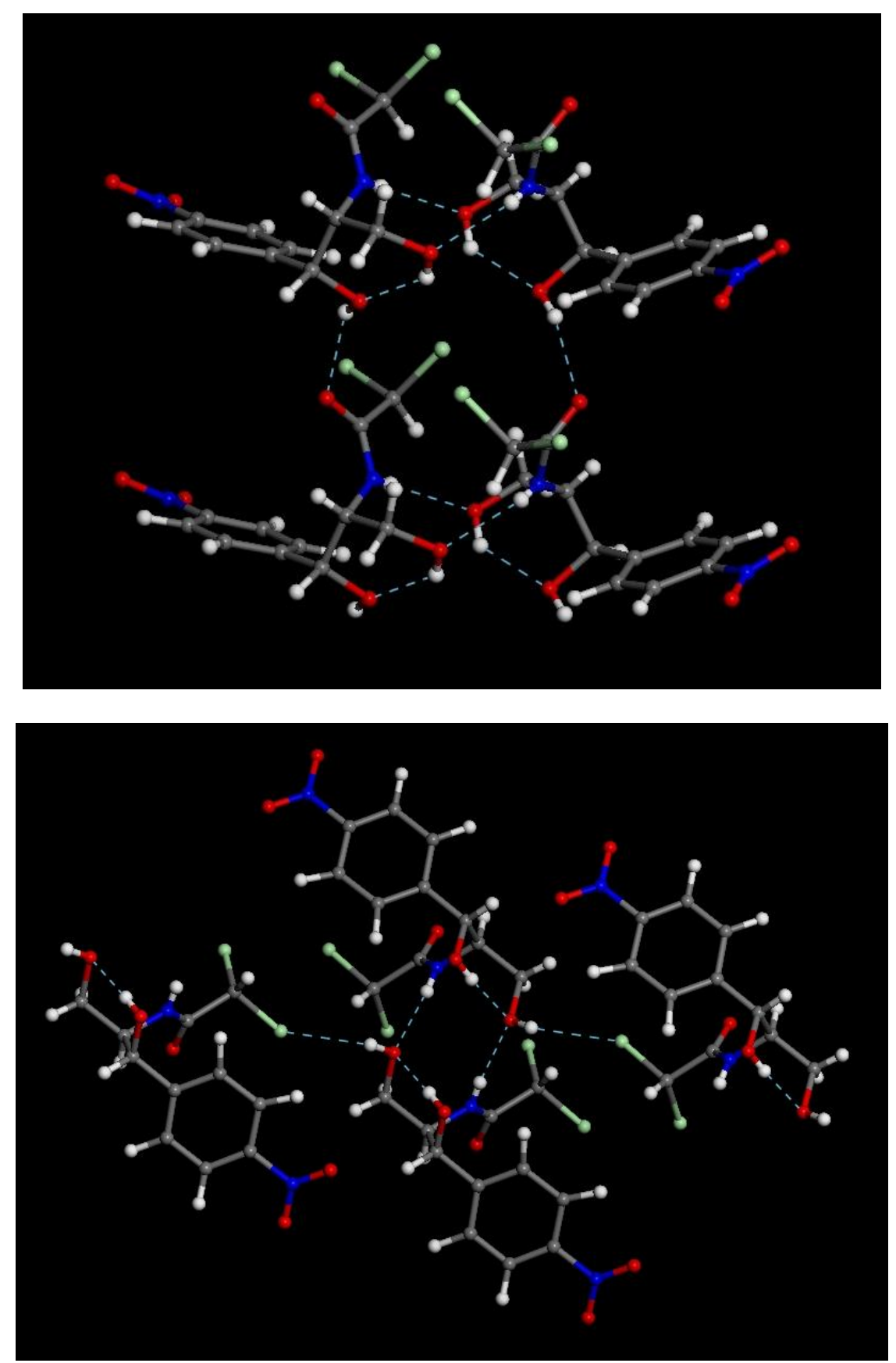

Fig. 2: Molecular models showing the conformers and the resulting hydrogen bonding patterns in the crystalline phase proposed by a) Chatterjee [7] and b) Acharya [8].

The X-H stretching region for pure crystalline CHL at room temperature (Fig. 3) can be used to guess the correct crystalline structure. As can be seen, pure crystalline CHL shows three bands located at about 3476,3345 and $3262 \mathrm{~cm}^{-1}$. The, the band at $3262 \mathrm{~cm}^{-1}$ can be attributed to N-H stretching in crystalline CHL (N-H stretching of crystalline secondary amides typically occurs at about $3260 \mathrm{~cm}^{-1}$ [18]). Hence, the bands located at 3476 and $3345 \mathrm{~cm}^{-1}$ can be attributed to the 
two $\mathrm{OH}$ groups present in CHL. The band at $3345 \mathrm{~cm}^{-1}$ is strongly red shifted (free $\mathrm{OH}$ stretching occurs in the $3650-3600$ $\mathrm{cm}^{-1}$ range [18]) and can be only attributed to hydroxyl stretching in cooperatively hydrogen bonded O-H $\cdots \mathrm{O}-\mathrm{H}$ systems. Hence, the degree of hydrogen bonding cooperativity has been analyzed using a simple method recently proposed by Ohno et al. [19]. In this method, each $\mathrm{O}-\mathrm{H} \cdots \mathrm{O}-\mathrm{H}$ couple is considered a donor-acceptor (DA) group, and the interactions established by $\mathrm{D}$ or $\mathrm{A}$ with the surrounding molecules are assumed to strengthen or weaken the hydrogen bonding interaction between $\mathrm{D}$ and $\mathrm{A}$. The number of protons accepted by $\mathrm{D}$ is termed $a_{D}$ (in the $0-2$ range), the number of protons accepted by $\mathrm{A}$ is $a_{A}(0-1)$ and the number of protons donated by $\mathrm{A}$ is $d_{A}(0-1)$. The hydrogen bonding structure adopted by the DA couple with its surroundings is then characterized by the $a_{D} D A d_{A} a_{A}$ string, and the strength of the DA hydrogen bond is classified according to the cooperativity indicator $M_{O H}=a_{D}+d_{A}-a_{A}$, proportional to the hydrogen bonding energy [19]. Applying this procedure to the $\mathrm{N}-\mathrm{H} \cdots \mathrm{O}-\mathrm{H} \cdots \mathrm{O}-\mathrm{H} \cdots \mathrm{O}=\mathrm{C}$ chains occurring in the crystalline structure proposed by Chatterjee (Fig. 2a) results in the 1DA10 string and $\mathrm{M}_{\mathrm{OH}}=2$, but in case of the bifurcated $(\mathrm{N}-\mathrm{H})(\mathrm{O}-\mathrm{H})>\mathrm{O}-\mathrm{H} \cdots \mathrm{Cl}-\mathrm{C}$ structures occurring in the crystalline structure proposed by Acharya, (Fig. 2b) the string is 0DA11 and the indicator is $\mathrm{M}_{\mathrm{OH}}=0$. Hence, the band at $3345 \mathrm{~cm}^{-1}$ can be rationalized assuming the crystalline structure proposed by Chatterjee (in fact, it is close to the peak reported for other compounds with $\mathrm{M}_{\mathrm{OH}}=2$, such as liquid tetrols [20]), but cannot be assigned to any interaction occurring in the crystalline structure proposed by Acharya. Finally, the remaining band at $3476 \mathrm{~cm}^{-1}$ can be attributed to the $\mathrm{O}-\mathrm{H} \cdots \mathrm{O}=\mathrm{C}$ interactions (usually occurring in the range $3600-3450 \mathrm{~cm}^{-1}$ [18]) present in the model proposed by Chatterjee.

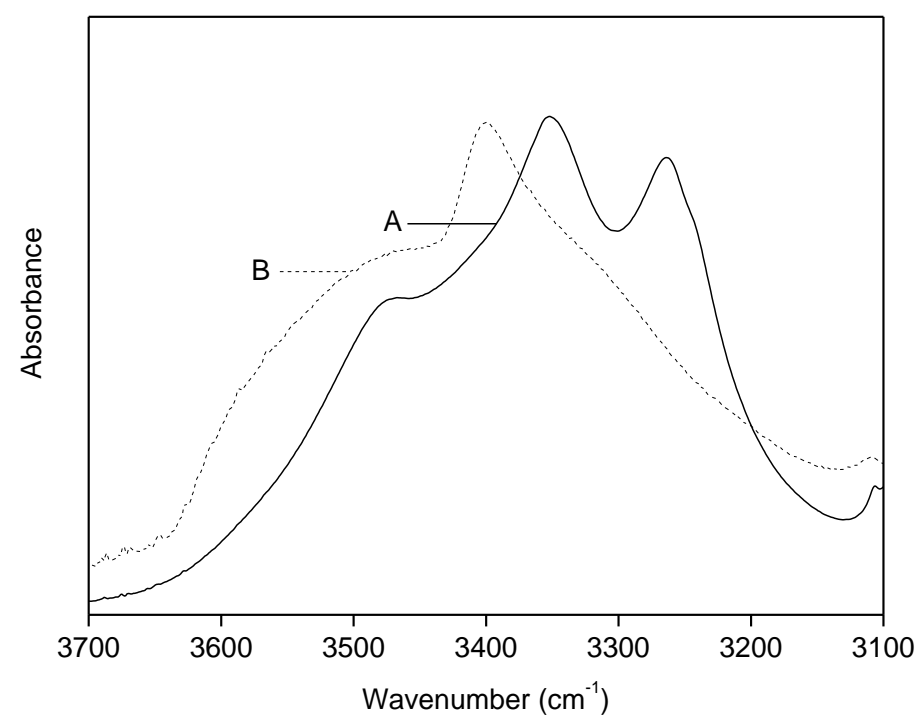

Fig. 3: Hydroxyl stretching region for pure crystalline $\mathrm{CHL}(\mathrm{A})$, and molten $\mathrm{CHL}$ at $160{ }^{\circ} \mathrm{C}(\mathrm{B})$.

\subsection{Ab Initio Quantum Mechanical calculations}

$\mathrm{Ab}$ initio QM calculations have been carried out to analyze the conformational preferences of free CHL molecules in solution. Assuming that the amide bond prefers the anti conformation, CHL contains seven potential rotatable bonds (see Fig. 1). The first four dihedrals determine to a large extent the overall shape of the molecule, while the remaining three only affect to the orientation of the terminal groups. These three dihedrals $\left(\phi_{5}-\phi_{7}\right)$ are actually the most conflicting ones; $\phi_{5}$ fixes the orientation of the terminal dichloromethane group and $\phi_{6}$ and $\phi_{7}$ establish the orientation of the secondary and the primary hydroxyl groups respectively. Table 1 reports the geometries for the two solution conformers proposed by Bustard and Höltje $[10,11]$. Conformer 2 allows intramolecular hydrogen bonding since $\phi_{3}$ is gauche, but conformer 1 does not, contradicting the investigation of Jardetzky [9]. A definitive study has been claimed [2]. 
Table 1: Dihedrals proposed by Höltje [11] for the two most stable conformes of CHL in solution. The dihedrals corresponding to the crystalline conformers proposed by Chatterjee [7] and Acharya [8] are also shown for comparison.

\begin{tabular}{|c|c|c|c|c|c|}
\hline Dihedral & Reference atoms & Conf. 1 & Conf. 2 & Chatterjee & Acharya \\
\hline$\phi_{1}$ & $\mathrm{C}_{\mathrm{a}} \mathrm{C}_{\mathrm{a}} \mathrm{CC}$ & 90 & 90 & 91 & 95 \\
\hline$\phi_{2}$ & $\mathrm{C}_{\mathrm{a}} \mathrm{CCN}$ & -60 & -60 & -55 & -58 \\
\hline$\phi_{3}$ & $\mathrm{CCCO}$ & 180 & 60 & 72 & 70 \\
\hline$\phi_{4}$ & $\mathrm{HCNH}$ & 180 & 180 & -162 & 175 \\
\hline$\phi_{5}$ & $\mathrm{OCCH}$ & 60 & 60 & -171 & -162 \\
\hline$\phi_{6}$ & $\mathrm{C}_{\mathrm{a}} \mathrm{COH}$ & -60 & 180 & -18 & 146 \\
\hline$\phi_{7}$ & $\mathrm{CCOH}$ & -60 & 30 & -42 & -124 \\
\hline
\end{tabular}

Hence, the conformational behavior of CHL in solution has been revisited here. The conformational search has been simplified considering the minimal amount of reliable results already reported. The minimum of $\phi_{1}$ is known to be at about $90^{\circ}$ [21]. Bustard [10] concluded using NMR spectroscopy that $\phi_{4}$ adopts the anti conformation. In addition, $\phi_{5}$ is known to adopt both the anti and syn conformations in condensed phases (though it prefers exclusively the syn conformation in vacuum) [22]. Hence, $\phi_{1}=90^{\circ}, \phi_{4}=180^{\circ}$ and $\phi_{5}=0^{\circ} \& 180^{\circ}$ have been assumed here. Regarding $\phi_{2}, \phi_{3}, \phi_{6}$ and $\phi_{7}$ the anti and gauche \pm rotamers have been considered. Therefore, 162 molecular models have been built and optimized at the B3LYPD3/DZP level of theory. The six conformers of lower energy have been identified and reoptimized at the B3LYP-D3/def2TZVP(-f) level of theory using tight convergence criteria (all of them are true minima as confirmed by the absence of negative frequencies in the vibrational analyses at the same level of theory). To account for the solvent effects, the Kirkwood-Onsager self-consistent reaction field (SCRF) method has been applied in all the computations [23] using a cavity radius $\mathrm{R}=4.4 \AA$ (as determined from the density of amorphous CHL, $1.47 \mathrm{~g} / \mathrm{cm}^{3}[24]$ ) and the dielectric constant of acetonitrile $\varepsilon=37.5$.

Table 2 shows the dihedral angles for the 6 conformers of lower energy obtained in this conformational analysis. As can be seen, dilute CHL solutions in acetonitrile should contain mainly conformers I and II in similar amounts (see Figure 4 for geometries). These two conformers adopt similar geometries (they only differ in the orientation of the dichloromethyl group, determined by $\phi_{5}$ ) and show similar energies. Our results discard the prevalence of conformer 1 (the non-autoassociated one of Bustard and Höltje, see table 1); in fact, the free energy of the conformers with $\phi_{3}=180^{\circ}$ (conformers V and VI in table 2) is about $20 \mathrm{~kJ} / \mathrm{mol}$ larger than that of conformer $\mathbf{I}$. In addition, conformer 2 of Höltje is not also a true minimum since optimization of this geometry results in a final structure with $\phi_{7} \sim 180^{\circ}$ (corresponding to conformer $\mathbf{I}$ ).
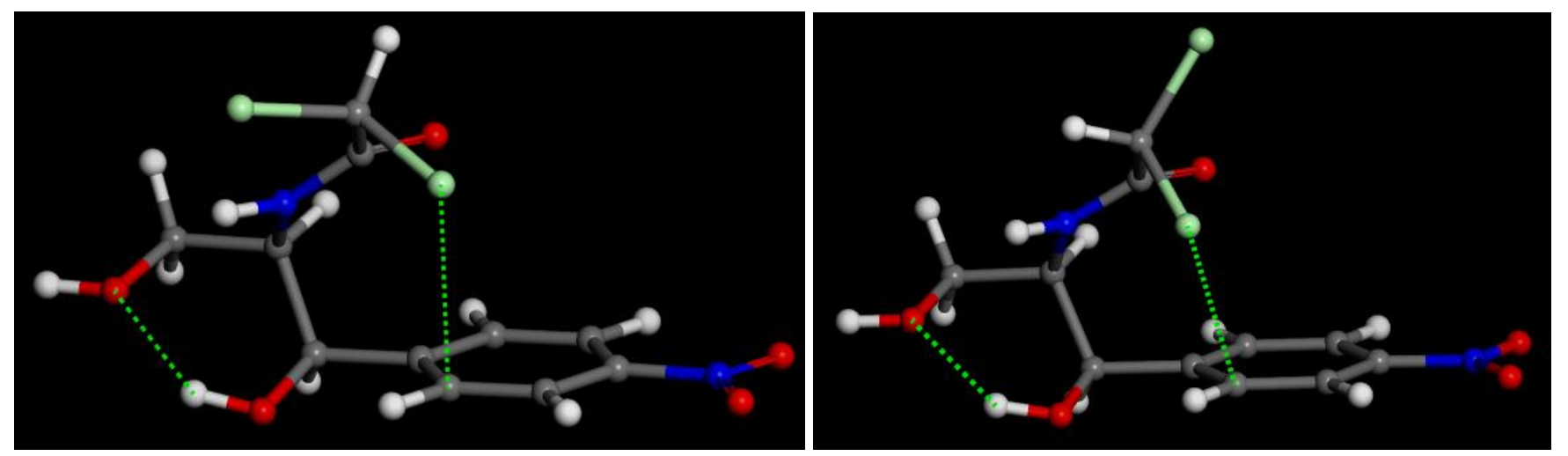

Fig. 4: Equilibrium geometries for conformers I (left) and II (right) in acetonitrile at the B3LYP-D3/def2-TZVP(-f) level of theory. 
Table 2: Dihedral angles, energies and populations of the six lower energy conformers of CHL in acetonitrile solution optimized at the B3LYP-D3/def2-TZVP(-f) level of theory.

\begin{tabular}{|l|l|l|l|l|l|l|}
\hline Dihedral & I & II & III & IV & V & VI \\
\hline$\phi_{1}\left(\mathrm{C}_{\mathrm{a}} \mathrm{C}_{\mathrm{a}} \mathrm{CC}\right)$ & 102 & 105 & 112 & 106 & 101 & 101 \\
\hline$\phi_{2}\left(\mathrm{C}_{\mathrm{a}} \mathrm{CCN}\right)$ & -64 & -67 & -53 & -64 & -61 & -64 \\
\hline$\phi_{3}(\mathrm{CCCO})$ & 64 & 65 & -41 & -50 & -176 & -179 \\
\hline$\phi_{4}(\mathrm{HCNH})$ & 153 & 152 & 164 & 161 & 154 & 146 \\
\hline$\phi_{5}(\mathrm{OCCH})$ & 42 & 160 & 40 & 160 & 44 & 162 \\
\hline$\phi_{6}\left(\mathrm{C}_{\mathrm{a}} \mathrm{COH}\right)$ & 166 & 169 & -161 & -153 & -158 & -153 \\
\hline$\phi_{7}(\mathrm{CCOH})$ & 176 & 177 & -170 & -176 & -179 & 180 \\
\hline$\mu(\mathrm{D})$ & 19.7 & 21.4 & 18.0 & 20.1 & 18.3 & 20.2 \\
\hline$\Delta \mathrm{E}(\mathrm{kJ} / \mathrm{mol})$ & 0 & 0.604 & 15.82 & 18.84 & 27.08 & 27.07 \\
\hline$\Delta \mathrm{G}^{\mathbf{o}}(\mathrm{kJ} / \mathrm{mol})$ & 0.352 & 0 & 13.64 & 13.90 & 20.86 & 21.05 \\
\hline $\mathrm{N}_{\mathrm{i}} / \mathrm{N}(\%)$ & 46.25 & 53.31 & 0.22 & 0.20 & 0.01 & 0.01 \\
\hline
\end{tabular}

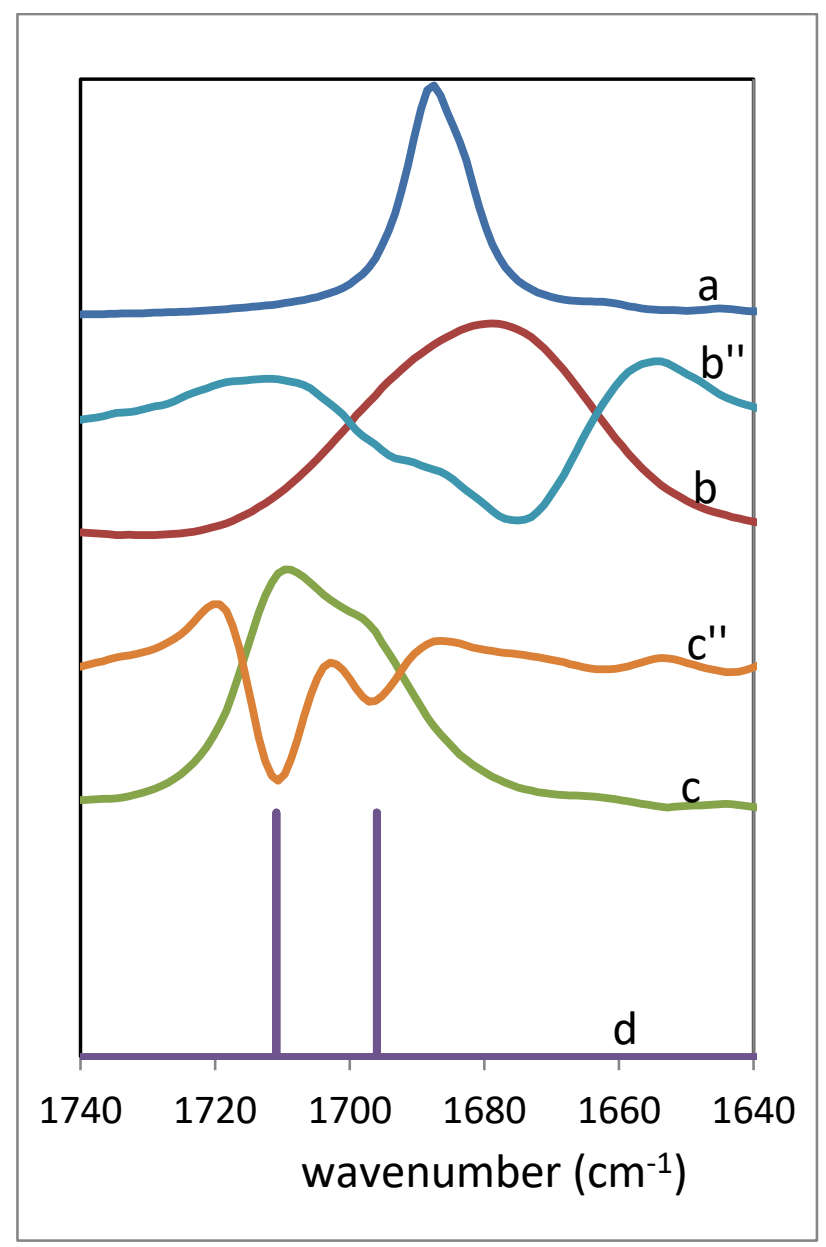

Fig. 5: Carbonyl stretching region of CHL and second derivatives ('”) of: a) crystalline $\mathrm{CHL}$ at $40^{\circ} \mathrm{C}$; b) supercooled $\mathrm{CHL}$ at $40{ }^{\circ} \mathrm{C}$; c) CHL in acetonitrile solution (1 wt\%); d) computed spectrum of CHL in acetonitrile solution at the B3LYP-D3/def2-TZVP(-f) level of theory (scaling factor 0.9834).

Finally, FTIR spectroscopy has been used to find experimental support for the QM results. Figure 5 shows the Amide I stretching region of CHL. Pure crystalline CHL displays a narrow peak at about $1687 \mathrm{~cm}^{-1}$. Supercooled CHL shows a broad 
Amide I envelope that can be resolved using second derivative techniques in two components, suggesting the existence of two conformers. The spectrum of CHL in dilute acetonitrile (ACN) solution (1 wt \%) shows splitting in the Amide I region, and the locations of the two components determined using second derivative FTIR spectroscopy are 1697 and $1710 \mathrm{~cm}^{-1}$. The locations obtained in the vibrational analysis at the B3LYP-D3/def2-TZVP(-f) level of theory are (after application of 0.9834 scaling factor), are 1696 and $1711 \mathrm{~cm}-1$ (see Fig. 5). Hence, there is a very good agreement between the computed results and the experimental spectrum in the Amide I region. The conformational sensitivity of the $\mathrm{C}=\mathrm{O}$ group can be attributed to the presence of electronegative (chlorine) atoms in the alpha carbon relative to the $\mathrm{C}=\mathrm{O}$ group [25, 22, 26, 27].

\section{Conclusion}

The conformational behavior of CHL has been has been revisited. According to the analysis of the crystalline $\mathrm{OH}$ stretching region, CHL crystallizes in the conformation proposed by Chatterjee [7], and not in the conformation proposed by Acharya [8]. In the ordered phase, the primary hydroxyl group acts as hydrogen bond donor and the secondary hydroxyl group acts as acceptor.

Upon breaking the crystalline structure, the hydroxyl groups of CHL turn over so that the secondary hydroxyl group acts as hydrogen bond donor and the primary one acts as acceptor, resulting in two conformers of similar energy that differ in the orientation of the dichloromethane group. The reversal of the intramolecular hydrogen bond allows the molecule to fold back further, reducing the Chlorine-aromatic ring distances in the stable conformers below $3.9 \AA$, suggesting therefore the formation of intramolecular $\mathrm{C}-\mathrm{Cl} \cdots \pi$ halogen bonds in both conformers.

\section{Acknowledgements}

The authors are thankful for funds from the Spanish Ministry of Innovation and Competitiveness MINECO (MAT201678527-P) and the Basque Government, Department of Education (IT-927-16).

\section{References}

[1] World He The reversal of the intramolecular hydrogen bond alth Organization (WHO), "Essential medicines," 2015. [Online]. Available: http://www.who.int/emlib/

[2] F. E. Hahn and P. Gund, "A Structural Model of the Chloramphenicol Receptor Site," in Drug Receptor Interactions in Antimicrobial Chemotherapy. Topics in Infectious Diseases, J. Drews and E. Hahn, Eds., Vienna, Springer, 1975, pp. 245-265.

[3] O. Pongs, "Chloramphenicol," in Mechanism of Action of Antibacterial Agents, F. E. Hahn ed., Berlin, Springer, 1979, pp. 26-42.

[4] T. R. Tritton, "Ribosome-chloramphenicol interactions: A Nuclear magnetic resonance study," Arch. Biochem. Biophys., vol. 197, pp. 10-17, 1979.

[5] G. P. Dinos, C. M. Athanassopoulos, D. A. Missiri, P. C. Giannopoulou, I. A. Vlachogiannis, G. E. Papadopoulos, D. Papaioannou and D. M. Kalpaxis, "Chloramphenicol Derivatives as Antibacterial and Anticancer Agents: Historic Problems and Current Solutions," Antibiotics, vol. 5, 2016.

[6] J. D. Dunitz, "The Crystal Structure of Chloramphenicol and Bromamphenicol," J. Am. Chem. Soc., vol. 74, p. 995999, 1952.

[7] C. Chatterjee, J. K. Dattagupta, N. N. Saha, W. Saenger and K. Müller, "Crystal and molecular structure of chloramphenicol," J. Cryst. Mol. Struct., vol. 9, pp. 295-304, 1979.

[8] K. R. Acharya, D. S. S. Gowda and M. Post, "The Structure of Chloramphenieol," Acta Cryst. B, vol. B35, pp. 1360$1363,1979$.

[9] O. Jardetzky, "Studies on the Mechanism of Action of Chloramphenicol. I. The Conformation of Chloramphenicol in Solution," J. Biol. Chem., vol. 238, pp. 2498-2508, 1963.

[10] T. M. Bustard, R. S. Egan and T. J. Perun, "Conformational studies on chloramphenicol and related molecules," Tetrahedron, vol. 29, no. 14, pp. 1961-1967, 1973.

[11] H. Höltje and L. B. Kier, "A theoretical Approach to Structure-Activity Relationships of Chloramphenicol and Congeners," J. Med. Chem., vol. 17, no. 8, pp. 814-819, 1974. 
[12] A. L. Fitzhugh, "Chloramphenicol: High dilution FT-IR evidence for an intramolecular hydrogen bond," Bioorg. Med. Chem. Lett., vol. 1, no. 5, pp. 257-262, 1991.

[13] A. A. Granovsky, "Firefly version 8," [Online]. Available: www http://classic.chem.msu.su/gran/firefly/index.html

[14] T. H. Dunning and P. J. Hay, "Gaussian Basis Sets for Molecular Calculations," in Methods of Electronic Structure Theory, H. F. Schaefer, ed., New York, Springer, 1977, pp. 1-27.

[15] F. Weigend and R. Ahlrichs, "Balanced basis sets of split valence, triple zeta valence and quadruple zeta valence quality for H to Rn: Design and assessment of accuracy," Phys. Chem. Chem. Phys., vol. 7, no. 18, pp. 3297-3305, 2005.

[16] D. Sajan, G. D. Sockalingum, M. Manfait, I. Hubert Joe and V. S. Jayakumar, "NIR-FT Raman, FT-IR and surfaceenhanced Raman scattering spectra, with theoretical simulations on chloramphenicol," J. Raman Spectrosc, vol. 39, pp. 1772-1783, 2008.

[17] G. R. Desiraju and T. Steiner, The Weak Hydrogen Bond: In Structural Chemistry and Biology. New York: Oxford University Press, 1999, pp. 217-219.

[18] G. Socrates, Infrared and Raman Characteristic Group Frequencies: Tables and Charts, 3 ed. Chichester: John Wiley and Sons, 2001.

[19] K. Ohno, T. Shimoaka, N. Akai and Y. Katsumoto, "Relationship between the Broad OH Stretching Band of Methanol and Hydrogen-Bonding Patterns in the Liquid Phase," J. Phys. Chem. A, vol. 112, pp. 7342-7348, 2008.

[20] J. Seehusen, D. Schwarzer, J. Lindner and P. Vöhringer, "Equilibrium and mid-infrared driven vibrational dynamics of artificial hydrogen-bonded networks," Phys. Chem. Chem. Phys., vol. 11, p. 8484-8495, 2009.

[21] Ö. Farkas, S. J. Salpietro, P. Császár and I. G. Csizmadia, "Conformations of ethylbenzene (CH3--CH2-Ph). An ab initio study," J. Mol. Structure (Theochem), vol. 367, pp. 25-31, 1996.

[22] S. L. Hinchley, H. E. Robertson, L. J. McLachlan, C. A. Morrison, D. W. H. Rankin, S. J. Simpson and E. W. Thomas, "Conformational Analysis with Both Experimental and Computational Data for Both Gaseous and Crystalline Phases: Unexpected Interactions in N-Methyldichloroacetamide," J. Phys. Chem. A, vol. 108, pp. 185-193, 2004.

[23] M. W. Schmidt, T. L. Windus and M. S. Gordon, "Structural Trends in Silicon Atranes," J. Am. Chem. Soc., vol. 117, no. 28, pp. 7480-7486, 1995.

[24] M. M. Knopp, L. Tajber, Y. Tian, N. E. Olesen, D. S. Jones, A. Kozyra, K. Löbmann, K. Paluch, C. M. Brennan, R. Holm, A. M. Healy, G. P. Andrews and T. Rades, "Comparative Study of Different Methods for the Prediction of Drug-Polymer Solubility," Mol. Pharm., vol. 12, pp. 3408-3419, 2015.

[25] M. F. Santos, C. B. Braga, T. C. Rozada, E. A. Basso and B. C. Fiorin, "Rotational isomerism of some chloroacetamides: Theoretical and experimental studies through calculations, infrared and NMR," Spectrochim. Acta A Mol. Biomol. Spectrosc., vol. 129, pp. 148-156, 2014.

[26] P. R. Olivato and R. Rittner, "Conformatinal and electronic interaction studies of some a-mono-heterosubstituted carbonyl compounds," Rev. Heteroat. Chem., vol. 15, pp. 115-159, 1996.

[27] B. C. Fiorin, E. A. Basso, C. F. Tormena, R. Rittner and R. J. Abraham, "Theoretical and Experimental Investigation on the Rotational Isomerism in a-Fluoroacetophenones," J. Phys. Chem. A, vol. 113, pp. 2009-2913, 2009. 